\title{
Laparoscopic Findings in Wilson's Disease without Cirrhosis
}

T. Sakai, K. Shiraki, T. Tada, H. Fuke, M. Tanabe, H. Inoue, K. Sugimoto, S. Ohmori, K. Takase, T. Nakano

First Dept. of Internal Medicine, Mie University School of Medicine, Tsu, Mie, Japan

Corresponding Author

K. Shiraki, M.D., Ph.D.

First Dept. of Internal Medicine Mie University School of Medicine 2-174 Edobashi

Tsu

Mie

Japan

Fax: +81-59-231-5201

E-mail: katsuyas@clin.medic.mie-u.ac.jp

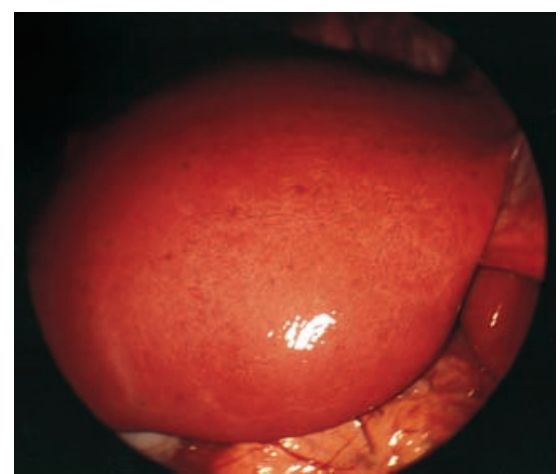

Figure 1 A 25-year-old man was referred to our hospital because of liver dysfunction with abnormal copper metabolism. Laparoscopic findings revealed a mild yellowish liver with smooth surface. There were multiple dark-bluish round spots $1-2 \mathrm{~mm}$ in diameter on the surface of both lobes, indicating uneven distribution of copper deposition. The patient was diagnosed as having the early stage of Wilson's disease.

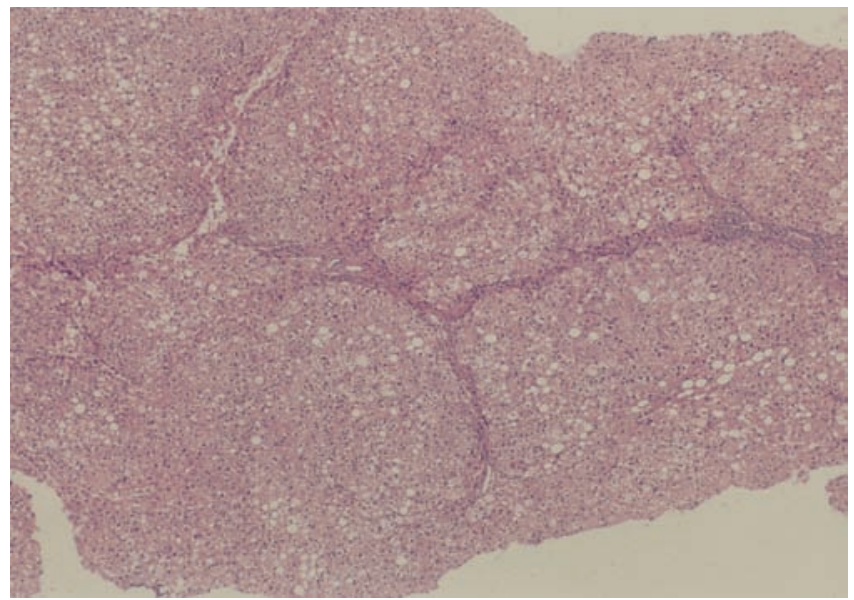

Figure 2 Histological findings revealed regenerative lobules with thin fibrous septa. In the parenchyma, fatty change was irregularly distributed, compatible with Wilson's disease (hematoxylin and eosin, original magnification $\times 100$ ). 